\title{
Animal Health Research Reviews \\ cambridge.org/ahr \\ Editorial: Systematic reviews reveal a need for more, better data to inform antimicrobial stewardship practices in animal agriculture
}

Jan M. Sargeant ${ }^{1,2}$ (D), Annette M. O'Connor ${ }^{3}$ (D) and Charlotte B. Winder ${ }^{1,2}$ (D)

\section{Letter}

Cite this article: Sargeant JM, O'Connor AM, Winder CB (2019). Editorial: Systematic reviews reveal a need for more, better data to inform antimicrobial stewardship practices in animal agriculture. Animal Health Research Reviews 20, 103-105. https://doi.org/10.1017/ S1466252319000240

Received: 25 November 2019

Accepted: 3 December 2019

\section{Key words:}

Antimicrobial stewardship; editorial; efficacy; systematic review

\section{Author for correspondence:}

Jan Sargeant, Department of Population Medicine, Ontario Veterinary College, University of Guelph, ON, Canada. E-mail: sargeanj@uoguelph.ca Production Animal Medicine, lowa State University College of Veterinary Medicine, IA, USA (c) The Author(s), 2020. This is an Open Access article, distributed under the terms of the Creative Commons Attribution licence (http:// creativecommons.org/licenses/by/4.0/), which permits unrestricted re-use, distribution, and reproduction in any medium, provided the original work is properly cited.
${ }^{1}$ Department of Population Medicine, Ontario Veterinary College, University of Guelph, ON, Canada; ${ }^{2}$ Centre for Public Health and Zoonoses, University of Guelph, ON, Canada and ${ }^{3}$ Department of Veterinary Diagnostic and

\begin{abstract}
This editorial summarizes the key observations from a special issue of Animal Health Research Reviews comprising 14 articles related to the efficacy of antimicrobial and non-antimicrobial approaches to reduce disease in beef, dairy cattle, swine, and broiler chickens. The articles used evidence-based methods, including scoping reviews, systematic reviews, meta-analyses, and network meta-analyses. Despite finding evidence of efficacy for some of the interventions examined, across the body of research, there was a lack of replication and inconsistency in outcomes among the included trials, and concerns related to completeness of reporting and trial design and execution. There is an urgent need for more and better data to inform antimicrobial stewardship practices in animal agriculture.
\end{abstract}

As the threat of antimicrobial resistance grows, stewardship of these vital drugs is increasingly important in both human and animal health. Important facets of antimicrobial stewardship include using antimicrobials judiciously as well as taking measures to minimize the need to use antimicrobials at all. In addition to treating clinical illness in animals, antimicrobials are sometimes used prophylactically (to prevent illness) or as metaphylaxis (to control disease in groups of animals, in situations in which some animals may be already diseased or infected). In order to make clinically appropriate decisions and to implement judicious use practices in food-producing animals, veterinarians and producers need to access evidence-based information about the relative efficacy of the antimicrobial and non-antimicrobial alternatives that are available.

To that end, the 14 articles in this special issue examined the publicly available body of evidence of relevance to antimicrobial stewardship in animal agriculture, with a focus on management practices intended to keep animals healthy and thereby reduce the need to use antimicrobials, as well as the administration of antimicrobials to prevent or control the disease. Each article describes the findings for specific research questions. However, there are several overarching conclusions from the articles as a whole:

Systematic reviews and other synthesis approaches are a valuable tool to aid in evidencebased decision-making. Evidence synthesis techniques, such as systematic reviews and meta-analyses, provide a scientifically rigorous means of evaluating the efficacy of a specific intervention across all studies investigating the efficacy of that intervention, and then present a concise summary of the available evidence. The articles in this special issue used formal evidence synthesis methods, including scoping reviews, systematic reviews, pairwise metaanalysis, and network meta-analysis, to evaluate selected strategies designed to reduce illness with non-antibiotic management practices or preventive antibiotic use. As network metaanalysis is quite novel in veterinary studies, an overview is provided of how to interpret the results of this approach to meta-analysis ( $\mathrm{Hu}$ et al., 2019).

Articles in this special issue include scoping reviews of systematic reviews in animal health (Vriezen et al., 2019a) and of non-antibiotic approaches to reduce the need for antibiotic treatments in beef and veal production (Wisener et al., 2019). The systematic reviews with meta-analyses or network meta-analyses include an assessment of the efficacy of vaccines and injectable antibiotics administered on arrival to control respiratory disease in feedlot cattle (O'Connor et al., 2019a, 2019b); the efficacy of teat sealants, antibiotics at dry off, selective dry cow treatment to reduce the incidence of mastitis and intra-mammary infection in early lactation, and the efficacy of antibiotics to treat clinical mastitis in dairy cattle (Winder et al., $2019 a, 2019 b, 2019 c, 2019 d)$; the comparative efficacy of litter type for preventing illness in broiler chickens (Sargeant et al., 2019a); the efficacy of antibiotics to prevent colibacillosis in broiler chickens (Sargeant et al., 2019b); and the efficacy of bacterial vaccines and of preventive antibiotics to prevent respiratory disease in swine (Sargeant et al., 2019c, 2019d). Finally, an evaluation of the methodological quality of systematic reviews and meta-analyses 
evaluating preventive antibiotics or management to reduce disease in livestock species is included (Vriezen et al., 2019b). Together, these articles provide both information on efficacy and comparative efficacy of several interventions to control animal diseases that are associated with the use of antibiotics, as well as insight into the current state of primary research addressing the efficacy of preventive antibiotics and management practices.

For some interventions, the body of evidence does provide some evidence of efficacy for some of the interventions. For example, a meta-analysis of clinical trials on the efficacy of teat sealants in dairy cows clearly shows that the products investigators studied are likely to be effective for reducing the incidence of mastitis and intra-mammary infection in early lactation (Winder et al., 2019a). Similarly, several antibiotics were effective at controlling bovine respiratory disease (O'Connor et al., 2019b). Understanding the comparative efficacy of antibiotic options is another tool to guide decision-making on prudent antibiotic use, enabling practitioners to use only antibiotics that are efficacious or, when multiple antibiotics are of similar efficacy, selecting the one of lesser importance in human medicine.

There is a lack of replication in the relevant research. A common issue across trials in the reviews was a lack of replication (i.e. multiple evaluations of the same outcome for the same intervention comparison). In some instances, intervention comparisons were only evaluated in a single trial, without a common intervention connecting that trial to another in the literature. The mastitis treatment review (Winder et al., 2019d), beef vaccine review (O'Connor et al., 2019a), and poultry litter review (Sargeant et al., 2019a) provide good examples of these disparate networks. The value of connected networks of evidence can be seen by contrasting the ability to reach conclusions for those reviews compared to the beef feedlot antibiotic review (O'Connor et al., 2019b), where the interventions were very well connected. There was also considerable variation in the outcomes measured used for specific disease conditions, both in the outcome definitions and in the period at risk for evaluating the outcome. For several of the reviews included in this issue, the insufficient volume and consistency of the published trials precluded the ability to conduct meaningful synthesis. Replication and consistency of outcomes is essential for building a robust evidence base.

Finally, improvements in study design and execution are needed. Numerous areas of concern were identified related to the design and execution of many of the trials included in the reviews. These included a lack of (or poor reporting of) random allocation of animals to intervention groups, as well as a failure to consider clustering of group-housed animals in the analysis. Adherence to the minimum reporting guidelines such as the REFLECT statement (O'Connor et al., 2010; Sargeant et al., 2010) and improvements in study design and execution are needed to address these deficiencies and to increase our confidence in the results of trials and reviews of trials.

These observations highlight again the value of systematic reviews; the reviews included in the special issue are shining a harsh light on issues related to replication, consistency of outcomes, completeness of reporting, and study design and execution that have been hidden in veterinary science for years. It is important to note that the issues identified in this body of work are characteristics of the evidence base, not the research synthesis methods. Narrative reviews and expert opinion based on these evidence bases would have the same issues, although it might not be as transparent. The advantage of formal research synthesis methods is the clarity with which these issues become evidence.
Ultimately, researchers along with public and private-sector research funders and other stakeholders should consider further coordination of scientific management and research resource allocation decisions to help drive improved study design and study replication for agricultural research addressing antibiotic use in food animals. As the articles in this special issue demonstrate, veterinarians and food-animal producers know far too little about scientifically validated prevention or control measures, including antibiotic efficacy and antibiotic alternatives that reliably support antibiotic stewardship. More and better research on these topics is urgently needed. With limited resources for research in veterinary science, it is essential that we maximize the value of trials by good conduct and reporting, consistent outcome measures, and replication.

\section{References}

Hu D, O'Connor AM, Winder CB, Sargeant JM and Wang C (2019) How to read and interpret the results of a Bayesian network meta-analysis: a short tutorial. Animal Health Research Reviews, THIS SPECIAL ISSUE.

O'Connor AM, Sargeant JM, Gardner I, Dickson J, Torrence M, Dewey CE, Dohoo I, Evans R, Gray J, Greiner M, Keefe G, Lefebvre S, Morley P, Ramirez A, Sischo W, Smith D, Snedeker K, Sofos J, Ward M and Wills R (2010) The REFLECT statement: methods and processes of creating reporting guidelines for randomized controlled trials for livestock and food safety. Zoonoses and Public Health 57, 95-104.

O'Connor AM, Hu D, Totton SC, Scott N, Winder CB, Wang B, Wang C, Glanville J, Wood H, White B, Larson R, Waldner C and Sargeant JM (2019a) A systematic review and network meta-analysis of bacterial and viral vaccines, administered at or near arrival at the feedlot, for control of bovine respiratory disease in beef cattle. Animal Health Research Reviews, THIS SPECIAL ISSUE.

O'Connor AM, Hu D, Totton SC, Scott N, Winder CB, Wang B, Wang C, Glanville J, Wood H, White B, Larson R, Waldner C and Sargeant JM (2019b) A systematic review and network meta-analysis of injectable antibiotic options for the control of bovine respiratory disease in the first 45 days post arrival at the feedlot. Animal Health Research Reviews, THIS SPECIAL ISSUE.

Sargeant JM, O'Connor AM, Gardner IA, Dickson JS, Torrence ME and Consensus Meeting Participants: Dohoo IR, Lefebvre SL, Morley PS, Ramirez A and Snedeker K (2010) The REFLECT Statement: reporting guidelines for randomized controlled trials in livestock and food safety: explanation and elaboration. Zoonoses and Public Health 57, 105-136.

Sargeant JM, Bergevin MD, Churchill K, Dawkins K, Deb B, Dunn J, Hu D, Logue CM, Meadows S, Moody C, Novy A, O'Connor AM, Reist M, Sato Y, Wang C and Winder CB (2019a) The efficacy of litter management strategies to prevent morbidity and mortality in broiler chickens: a systematic review and network meta-analysis. Animal Health Research Reviews, THIS SPECIAL ISSUE.

Sargeant JM, Bergevin MD, Churchill K, Dawkins K, Deb B, Dunn J, Logue CM, Novy A, O'Connor AM, Reist M and Winder CB (2019b) The efficacy of antibiotics to control colibacillosis in broiler poultry: a systematic review. Animal Health Research Reviews, THIS SPECIAL ISSUE.

Sargeant JM, Deb B, Bergevin MD, Churchill K, Dawkins K, Dunn J, Hu D, Moody C, O'Connor AM, O'Sullivan TL, Reist M, Wang C, Wilhelm B and Winder CB (2019c) Efficacy of bacterial vaccines to prevent respiratory disease in swine: a systematic review and network meta-analysis. Animal Health Research Reviews, THIS SPECIAL ISSUE.

Sargeant JM, Bergevin MD, Churchill K, Dawkins K, Deb B, Dunn J, Hu D, Moody C, O'Connor AM, O'Sullivan TL, Reist M, Wang C, Wilhelm B and Winder CB (2019d) A systematic review of the efficacy of antibiotics for the prevention of swine respiratory disease. Animal Health Research Reviews, THIS SPECIAL ISSUE.

Vriezen R, Sargeant JM, Vriezen E, Reist M, Winder CB and O'Connor AM (2019a) Systematic reviews and meta-analyses in animal health, performance, and on-farm food safety: a scoping review. THIS SPECIAL ISSUE. 
Vriezen R, Sargeant JM, Vriezen E, Winder CB and O'Connor AM (2019b) Quality assessment of systematic reviews and meta-analyses that examine preventive antibiotic uses and management practices designed to prevent disease in livestock. Animal Health Research Reviews, THIS SPECIAL ISSUE.

Winder CB, Sargeant JM, Hu D, Wang C, Kelton DF, Leblanc SJ, Duffield TJ, Glanville J, Wood H, Churchill KJ, Dunn J, Bergevin MD, Dawkins K, Meadows S, Deb B, Reist M, Moody C and O'Connor AM (2019a) Comparative efficacy of teat sealants given prepartum for prevention of intramammary infections and clinical mastitis: a systematic review and network meta-analysis. Animal Health Research Reviews, THIS SPECIAL ISSUE.

Winder CB, Sargeant JM, Hu D, Wang C, Kelton DF, Leblanc SJ, Duffield TJ, Glanville J, Wood H, Churchill KJ, Dunn J, Bergevin MD, Dawkins K, Meadows S, Deb B, Reist M, Moody C and O'Connor AM (2019b) Comparative efficacy of antimicrobial treatments in dairy cows at dry-off to prevent new intramammary infections during the dry period or clinical mastitis during early lactation: a systematic review and network meta-analysis. Animal Health Research Reviews, THIS SPECIAL ISSUE.

Winder CB, Sargeant JM, Kelton DF, Leblanc SJ, Duffield TJ, Glanville J, Wood H, Churchill KJ, Dunn J, Bergevin MD, Dawkins K, Meadows S and O'Connor AM (2019c) Comparative efficacy of blanket versus selective dry-cow therapy: a systematic review and pairwise meta-analysis. Animal Health Research Reviews, THIS SPECIAL ISSUE.

Winder CB, Sargeant JM, Hu D, Wang C, Kelton DF, Godkin MA, Churchill KJ and O'Connor AM (2019d) Comparative efficacy of antimicrobials for treatment of clinical mastitis in lactating dairy cattle: a systematic review and network meta-analysis. Animal Health Research Reviews, THIS SPECIAL ISSUE.

Wisener LV, Sargeant JM, O'Connor AM, O'Sullivan TL, McEwen SA, Nwosu A and Rossi TM (2019) Non-antibiotic approaches for disease prevention and control in beef and veal production: a scoping review. Animal Health Research Reviews, THIS SPECIAL ISSUE. 